\title{
Leucocoprinus Pat. (Agaricaceae, Basidiomycota) no Parque Estadual de Itapuã, Viamão, RS, Brasil ${ }^{1}$
}

\author{
Marcelo Somenzi Rother ${ }^{2,3}$ e Rosa Mara Borges da Silveira ${ }^{2}$
}

Recebido em 23/05/2007. Aceito em 31/10/2008

RESUMO - (Leucocoprinus Pat. (Agaricaceae, Basidiomycota) no Parque Estadual de Itapuã, Viamão, RS, Brasil). O presente trabalho descreve as espécies do gênero Leucocoprinus que ocorrem no Parque Estadual de Itapuã, município de Viamão, estado do Rio Grande do Sul, Brasil. Seis táxons foram encontrados: L. birnbaumii (Corda) Singer, L. brebissonii (Godey) Locq., L. cepistipes (Sowerby) Pat., L. cretaceus (Bull.) Locq., L. fragilissimus (Berk. \& M.A. Curtis) Pat. e L. cf. medioflavus (Boud.) Bon. São apresentados chave para identificação, descrições e ilustrações detalhadas dos caracteres macro e microscópicos, e comentários sobre a taxonomia e ecologia das espécies estudadas. Palavras-chave: Agaricales, cogumelos, taxonomia

ABSTRACT - (Leucocoprinus Pat. (Agaricaceae, Basidiomycota) species in Itapuã State Park, Viamão, Rio Grande do Sul State, Brazil). This work describes the species of Leucocoprinus found in Itapuã State Park, Viamão municipality, Rio Grande do Sul state, Brazil. Six species were found: L. birnbaumii (Corda) Singer, L. brebissonii (Godey) Locq., L. cepistipes (Sowerby) Pat., L. cretaceus (Bull.) Locq., L. fragilissimus (Berk. \& M.A. Curtis) Pat. and L. cf. medioflavus (Boud.) Bon. An identification key, detailed descriptions and illustrations of macro and microstructures, and comments on the taxonomy and ecology of the species are presented.

Key words: Agaricales, mushrooms, taxonomy

\section{Introdução}

As espécies do gênero Leucocoprinus Pat. pertencem ao clado Leucoagaricus/Leucocoprinus da família Agaricaceae Chevall (Vellinga 2004). São caracterizadas por apresentar hábito pluteóide, com basidiomas freqüentemente frágeis, membranosos a finamente carnosos; superfície do píleo geralmente flocosa-esquamulosa a fibrilosa com a margem normalmente estriada-sulcada; lamelas livres não mudando de cor com vapor de amônia; esporada branca, creme a amarelada; estípite central, com base mais alargada ou bulbosa, sem volva, apresentando anel. Basidiósporos geralmente hialinos, lisos, com parede espessa, com ou sem poro germinativo visível, geralmente dextrinóides, congófilos, metacromáticos em Azul de Cresil; basídios tetrasporados; pleurocistídios ausentes; queilocistídios presentes; superfície pilear muito variável, formada por uma mistura de diferentes tipos de células; trama himenoforal trabecular e fíbulas ausentes. Crescem no solo ou em madeira nos mais diversos ambientes, ocorrendo com maior freqüência no hemisfério Sul, comumente nas regiões tropicais e subtropicais, sendo consideradas mais raras para as regiões temperadas (Heinemann 1977; Pegler 1986; Singer 1986; Vellinga 2001; 2004; Wasser 1993).

Segundo Singer (1986), 13 espécies eram conhecidas para o gênero. Com base na revisão de trabalhos anteriores, Wasser (1993) mencionou 15-18 espécies. Os dados mais atualizados são os de Kirk et al. (2001), que citam 40 espécies conhecidas para a ciência. Certamente este número é muito superior e somente com mais trabalhos, principalmente em regiões tropicais, será possível estimar a diversidade desse gênero.

Vários autores contribuíram para o conhecimento de Leucocoprinus sensu lato no Brasil (Albuquerque et al.
2006; Bononi et al. 1981; 1984; Capelari 1989; Capelari \& Gimenes 2004; Capelari \& Maziero 1988; Meijer 2001; 2006; Pegler 1997; Raithelhuber 1987a; b; Rick 1961; Singer 1953; Sobestiansky 2005, entre outros), porém poucos descreveram e/ou ilustraram as espécies mencionadas. Por não haver estudo detalhado sobre o grupo no território brasileiro, este trabalho tem como finalidade apresentar chaves de identificação, descrições e ilustrações detalhadas, e comentários sobre a taxonomia e ecologia das espécies que ocorrem no Parque Estadual de Itapuã.

\section{Material e métodos}

As coleções foram obtidas por coletas realizadas no período de abril/2005 a junho/2006, no Parque Estadual de Itapuã (30'20'-30'27'S e $\left.50^{\circ} 50^{\prime}-51^{\circ} 05^{\prime} \mathrm{W}\right)$, unidade de conservação de proteção integral, localizada no município de Viamão, na região metropolitana de Porto Alegre, estado do Rio Grande do Sul. Uma descrição detalhada da área de estudo é apresentada em Silva et al. (2006).

A análise das características macroscópicas foi baseada em Largent (1977), com o auxílio de microscópio estereoscópico. As cores foram avaliadas utilizando-se a carta de cores de Kornerup \& Wanscher (1978). Para a análise microscópica foram realizados cortes manuais no basidioma e montadas lâminas com solução aquosa de hidróxido de potássio a $5 \%(\mathrm{KOH})$ juntamente com o corante vermelho congo $1 \%$ (Congo Red) e também com reagente de Melzer, segundo Largent et al. (1986). As medidas, observações e ilustrações das microestruturas foram efetuadas com o auxílio de uma ocular milimetrada e câmara clara acopladas ao microscópio óptico. Nas medidas dos basidiósporos, Q corresponde ao quociente entre o comprimento e a largura de cada basidiósporo e Qm é a média aritmética de Q. Os nomes dos autores das espécies foram abreviados de acordo com Authors of Fungal Names (CABI 2008).

Todo material identificado foi incorporado no Herbário do Instituto de Biociências da Universidade Federal do Rio Grande do Sul (ICN).

\section{Resultados e discussão}

Durante as 18 visitas realizadas no Parque Estadual de Itapuã foram identificadas seis espécies pertencentes ao

\footnotetext{
Parte da Dissertação de Mestrado do primeiro Autor

2 Universidade Federal do Rio Grande do Sul, Instituto de Biociências, Departamento de Botânica, Porto Alegre, RS, Brasil

3 Autor para correspondência: msrbio@yahoo.com.br
} 
gênero Leucocoprinus: L. cretaceus e L. cepistipes foram encontradas sobre madeira, sendo a primeira em tronco de árvore viva e a segunda em tronco em decomposição; as demais espécies ocorreram no solo. A localidade do
Parque com maior ocorrência de táxons foi a Praia da Pedreira. Das espécies identificadas, L. birnbaumii e L. cepistipes são consideradas comuns para o estado do Rio Grande do Sul.

\section{Chave para as espécies de Leucocoprinus}

1. Basidiósporos inamilóides, sem poro germinativo visível. 6. L. cf. medioflavus

1. Basidiósporos dextrinóides (pseudoamilóides), com poro germinativo visível 2

2. Basidiomas amarelos, se branco-amarelados, então com consistência membranosa 3

3. Basidiomas muito frágeis, deliqüescentes, com a superfície do píleo totalmente plicada e quase translúcida

5. L. fragilissimus

3. Basidiomas mais resistentes, consistência carnosa e a superfície do píleo com margem plicada

1. L. birnbaumii

2. Basidiomas brancos, geralmente carnosos

4. Estípite com a superfície coberta por esquâmulas flocosas brancas facilmente removidas na manipulação

4. L. cretaceus

4. Estípite com a superfície glabra

5. Superfície do píleo coberta por fibrilas castanhas a castanho-amareladas, basidiósporos (8-)8,5$10(-11) \times 6-7 \mu \mathrm{m}$

3. L. cepistipes

5. Superfície do píleo coberta por fibrilas castanho-acinzentadas, basidiósporos $10-11,5(-14) \times(5-) 6-7 \mu \mathrm{m}$

2. L. brebissonii

\section{Leucocoprinus birnbaumii (Corda) Singer, Sydowia} 15(1-6): 67 (1962) [1961].

Agaricus birnbaumii Corda, Icon. fung. (Prague) 3: 48 (1839).

Fig. 1-5, 30

Píleo 20-40 mm quando expandido, inicialmente hemisférico tornando-se plano-convexo a aplanado na maturidade, com ou sem umbo; amarelo-claro (1.A5), amarelolimão (1.A8) a amarelo (2.A8), com o umbo amarelo (3.B8) a alaranjado (4.B8); superfície seca, coberta por esquâmulas flocosas, facilmente removíveis, de coloração amarela; bordas planas, com margem plicada até um terço do píleo; contexto carnoso, muito fino, de coloração clara. Lamelas livres, amarelo-pálidas (2.A3), próximas, membranosas, apresentando lamélulas. Estípite 50-80×3-5 mm, central, clavado a levemente bulboso (acima de $7 \mathrm{~mm}$ ), amarelo-claro, amarelo-limão a amarelo, superfície coberta ou não com minúsculas esquâmulas flocosas, amarelo-claras; fistuloso, de consistência fibrosa; contexto amarelo-claro. Anel súpero, ascendente, amarelo, simples, membranoso, fugaz. Odor indistinto.

Basidiósporos (7,5-)8-10(-11)×5-7,5 $\mu \mathrm{m}, \mathrm{Q}=1,25-1,67$, $\mathrm{Qm}=1.40$, elipsóides a ovóides, hialinos, parede espessa $\mathrm{e}$ lisa, com poro germinativo evidente, dextrinóides (pseudoamilóides), congófilos, metacromáticos em Azul de Cresil. Esporada branca (1.A1). Basídios 16-41×8-10(-12) $\mu \mathrm{m}$, clavados, hialinos, parede fina e lisa, com 4 esterigmas de 3-․․ $\mu \mathrm{m}$ de comprimento. Pleurocistídios ausentes. Queilocistídios (32-)37-51(-72)×8-15 $\mu \mathrm{m}$, dispersos em tufos, de formas variáveis (ventricosos, estreitamente clavados, mucronados), hialinos, parede fina e lisa. Camada cortical do píleo formada por hifas hialinas a levemente castanhoamareladas de parede fina e lisa, com conteúdo celular de formas variadas (H, T, Y), 4-18 $\mu$ m. Fíbulas ausentes. Trama himenoforal trabecular, formada por hifas hialinas de parede fina e lisa, 3-12 $\mu \mathrm{m}$.

Hábito e habitat: solitário ou gregário, encontrado no solo no interior da mata.

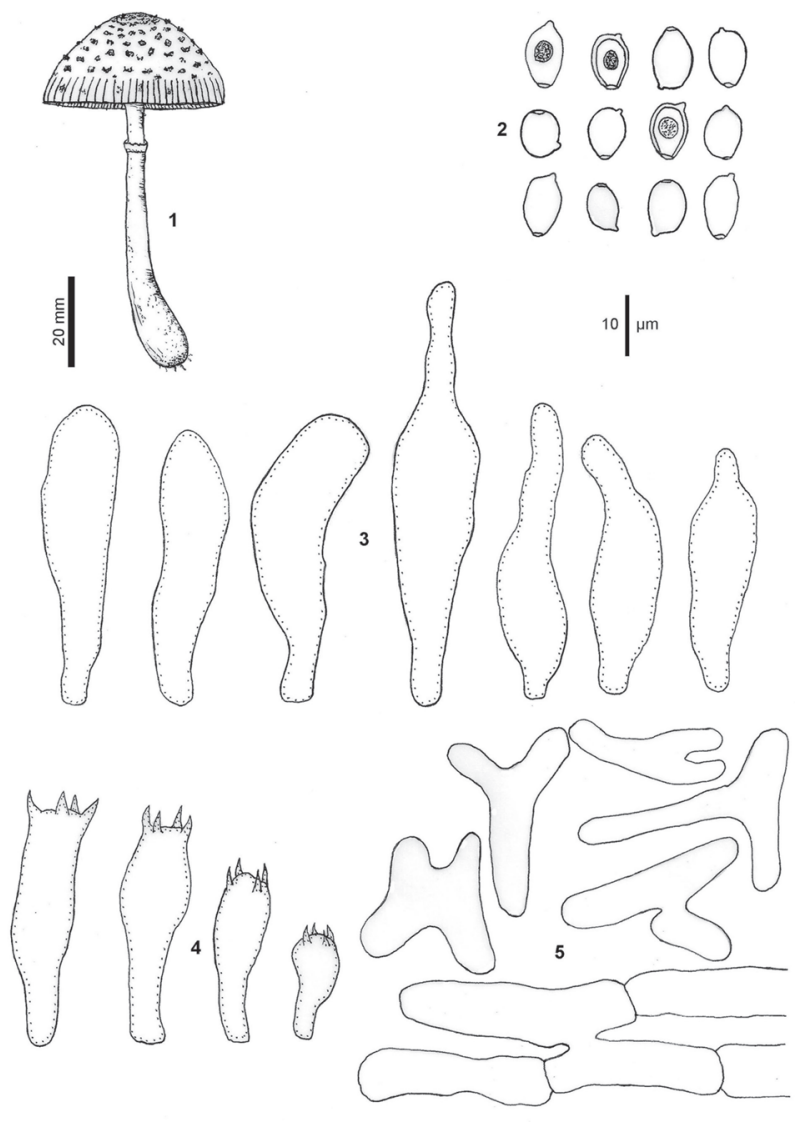

Figura 1-5. Leucocoprinus birnbaumii (Corda) Singer. 1. Basidioma. 2. Basidiósporos. 3. Queilocistídios. 4. Basídios. 5. Hifas da camada cortical do píleo. 
Material examinado: BRASIL. Rio Grande do Sul: Viamão, Parque Estadual de Itapuã, Encosta do Morro da Grota, 25/VI/2005, M.S. Rother 067/05 (ICN); Praia da Pedreira, 9/IV/2005, M.S. Rother 003/05 (ICN); M.S. Rother 008/05 (ICN); 27/I/2006, M.S. Rother 113/06 (ICN).

Distribuição: Europa: Bon (1981); Breitenbach \& Kränzlin (1995); Candusso \& Lanzoni (1990); Vellinga (2001). Ásia: Pegler (1972; 1986); Wasser (1993). África: Heinemann (1977); Pegler (1977). Américas: Dennis (1970); Meijer (2001; 2006); Pegler (1983; 1997); Raithelhuber (1987a); Wright \& Albertó (2002).

Comentários: a espécie é caracterizada por apresentar basidioma amarelado, píleo de consistência carnosa com margem plicada e basidiósporos com poro germinativo evidente. Segundo Candusso \& Lanzoni (1990), L. birnbaumii tem sido mencionada em muitos trabalhos pela beleza particular, não apresentando dificuldades em sua determinação. De acordo com Pegler (1983), esta espécie poderia ser confundida com L. sulphurellus Pegler pela pigmentação amarelada do basidioma. No entanto, L. sulphurellus é facilmente diferenciado pela coloração azul-esverdeada brilhante das lamelas quando machucadas, presença de pleurocistídios, basidiósporos menores (6-7×3,7-4,5 $\mu \mathrm{m})$ e por não apresentar margem do píleo plicada-estriada. Recentemente, Capelari \& Gimenes (2004) descreveram para o Brasil L. brunneoluteus, espécie próxima de L. birnbaumii, diferindo macroscopicamente por apresentar umbo castanho-escuro distinto, coloração das escamas castanha e consistência membranácea do basidioma, lembrando a consistência de L. fragilissimus. Segundo Franco-Molano et al. (2000), L. birnbaumii é muito tóxica e a ingestão deve ser evitada. Apesar de não ter sido coletada muitas vezes no Parque Estadual de Itapuã, é considerada espécie comum (Vellinga 2001) e típica de clima tropical a subtropical, ocorrendo nos dias quentes e úmidos do outono (Wright \& Albertó 2002). No Brasil, foi citada para o Sudeste (Capelari 1989; Grandi et al. 1984; Pegler 1997) e para a região Sul (Albuquerque et al. 2006; Meijer 2001; 2006; Sobestiansky 2005).

2. Leucocoprinus brebissonii (Godey) Locq., Bull. mens. Soc. linn. Lyon 12: 95 (1943).

Lepiota brebissonii Godey, Hyménomyc. Eur. (Paris): 64 (1874).

Fig. 6-10, 31

Píleo $34 \mathrm{~mm}$, aplanado; branco (1.A1) com superfície seca coberta por fibrilas e esquâmulas flocosas apressas, castanho-acinzentadas (5.C2) no disco central e mais claras próximas à margem; bordas planas com margem plicada até o centro; contexto muito fino de coloração branca. Lamelas livres, brancas (1.A1), levemente próximas, membranosas, apresentando lamélulas. Estípite $47 \times 3 \mathrm{~mm}$, central, cilíndrico com base levemente mais alargada $(5 \mathrm{~mm})$, branco de superfície lisa; fistuloso de consistência fibrosa; contexto branco; rizomorfas de coloração branca; não apresentando micélio basal. Anel mediano a súpero, branco, simples, ascendente, membranoso, estreito e fino. Odor desagradável.

Basidiósporos 10-11,5(-14)×(5-)6-7 $\mu \mathrm{m}, \mathrm{Q}=1,57-2,00$, $\mathrm{Qm}=1,71$, elipsóides a ovóides, hialinos, parede espessa e lisa, com poro germinativo bem distinto, dextrinóides (pseudoamilóides), congófilos, metacromáticos em Azul de Cresil. Esporada branca (1.A1). Basídios (18-)21-23(-27)× 10-11,5(-13) $\mu \mathrm{m}$, clavados, hialinos, parede fina e lisa, com 4 esterigmas de 1,5-3,5 $\mu \mathrm{m}$ de comprimento. Pleurocistídios ausentes. Queilocistídios 30-64×11-17 $\mu \mathrm{m}$, clavados a estreitamente clavados, hialinos, parede fina e lisa. Camada cortical do píleo formada por hifas prostradas de parede fina e lisa, com alguns elementos cilíndricos eretos com o conteúdo castanho-claro, 4-12 $\mu \mathrm{m}$. Fíbulas ausentes. Trama himenoforal trabecular, formada por hifas hialinas de parede fina e lisa, 3-8 $\mu \mathrm{m}$.

Hábito e habitat: solitário, em solo no interior da mata.

Material examinado: BRASIL. Rio Grande do Sul: Viamão, Parque Estadual de Itapuã, Praia da Predreira, 22/X/2005, M.S. Rother 089/05 (ICN).
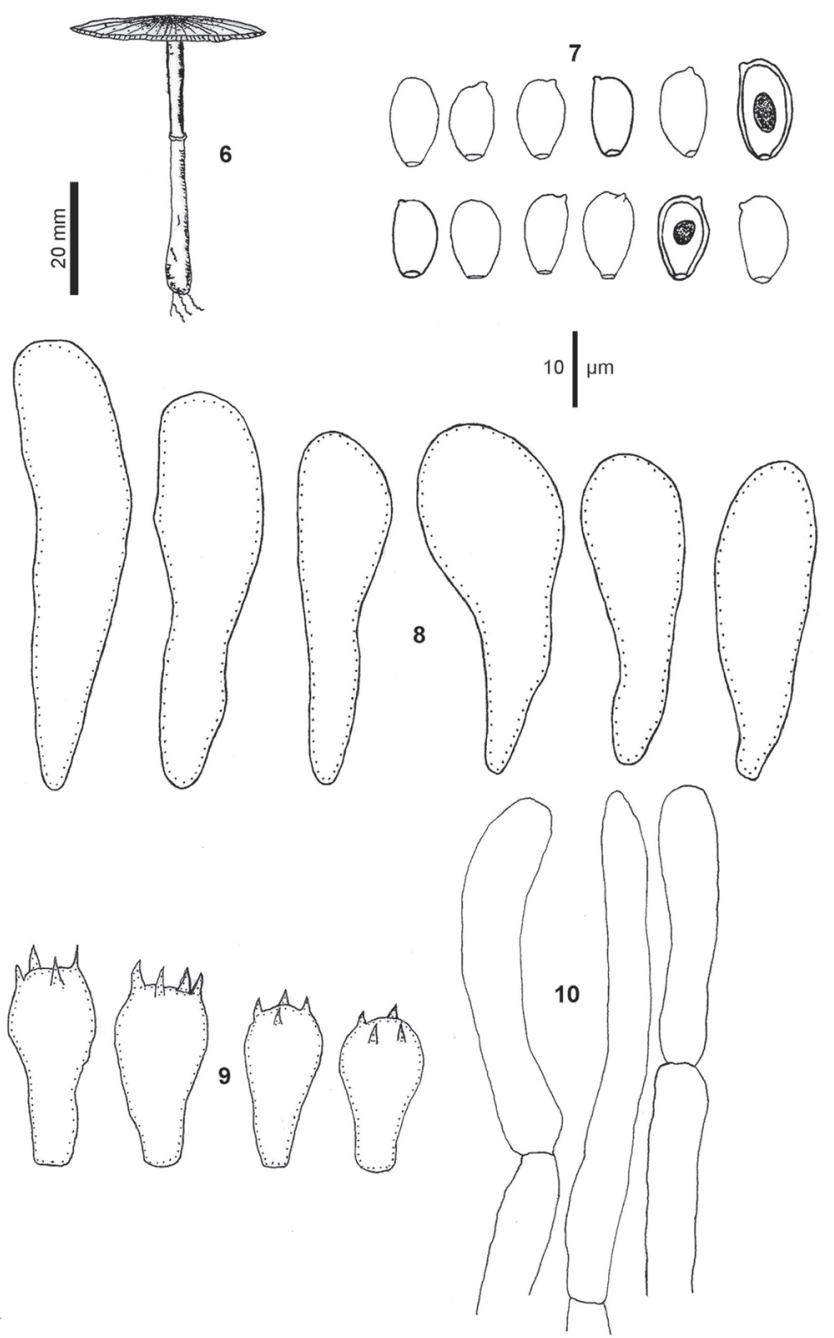

Figura 6-10. Leucocoprinus brebissonii (Godey) Locq. 6. Basidioma. 7. Basidiósporos. 8. Queilocistídios. 9. Basídios. 10. Elementos da camada cortical do píleo. 
Material adicional examinado: BRASIL. São Paulo: Cananéia, Ilha do Cardoso, encosta do Morro do Cardoso, 14/III/1984, M. Capelari 026 (SP); Pedro Luiz, 25/IV/1984, M. Capelari 093 (SP); Poço das Antas, 26/IV/1984, M. Capelari 122 (SP); entre Sítio Grande e Morro dos Três Irmãos, 23/X/1984, M. Capelari 167 (SP).

Distribuição: Europa: Bon (1981); Breitenbach \& Kränzlin (1995); Candusso \& Lanzoni (1990); Vellinga (2001). Ásia: Wasser (1993). África: Heinemann (1977). América do Sul: Pegler (1997).

Comentários: Leucocoprinus brebissonii é diferenciada das demais espécies do gênero por apresentar o píleo com coloração branca e o disco central variando de cinza-escuro, castanho-acinzentado, castanho-escuro a quase preto (Candusso \& Lanzoni 1990; Vellinga 2001; Wasser 1993). Todas as características microscópicas do material coletado conferem com as descritas por Bon (1981), Candusso \& Lanzoni (1990), Pegler (1997), Vellinga (2001) e Wasser (1993), com apenas uma variação nas características macroscópicas, referente à amplitude em que a margem do píleo é plicada. Quando esta característica é mencionada nos trabalhos consultados, a margem é plicada somente até um terço do diâmetro do píleo e não até o centro como observado no material. Uma das espécies que apresenta a margem plicada até o centro do píleo é L. fragilissimus, mas esta difere do material examinado por apresentar basidiomas bastante frágeis e delicados, píleo com a coloração mais clara e, microscopicamente, pela presença de esferocistos e ausência de queilocistídios. Segundo Dennis (1961), L. venezuelanus Dennis é muito semelhante a L. brebissonii, mas difere por apresentar basidiósporos menores (6-8x 4-5 $\mu \mathrm{m}$ ). Pela comparação com material depositado no herbário SP, foi possível a confirmação da espécie, embora o material coletado apresente coloração da superfície do píleo menos escurecida do que é geralmente citado na literatura. No Brasil, L. brebissonii já foi registrado para os estados de Rondônia (Capelari \& Maziero 1988), São Paulo (Capelari 1989; Pegler 1997) e, recentemente, para o Rio Grande do Sul (Albuquerque et al. 2006).

3. Leucocoprinus cepistipes (Sowerby) Pat., Journal de Bot., Paris 3: 336 (1889) [como 'cepaestipes'].

Agaricus cepistipes Sowerby, Coloured Figures of English

Fungi 1: tab. 2(1797) [1795-97].

Fig. 11-15, 32

Píleo 20-34 mm, inicialmente cônico, tornando-se hemisférico e por fim aplanado na maturidade; branco (1.A1), com superfície seca, coberta por esquâmulas flocosas castanhas (7.E5) a castanho-claras (6.D4) no disco central e por fibrilas recurvadas mais claras no restante do píleo; bordas planas, com margem plicada até um terço do píleo; contexto levemente carnoso, de coloração branca. Lamelas livres, brancas (1.A1), próximas, membranosas, apresentando lamélulas. Estípite 30-60×3-4 mm, central, cilíndrico, branco, com tom mais rosado próximo a base; superfície lisa; fistuloso, de consistência fibrosa; contexto branco. Anel mediano a súpero, branco, simples, ascendente, membranoso, estreito, fino e fugaz. Odor desagradável.

Basidiósporos (8-)8,5-10(-11) ×6-7 $\mu \mathrm{m}, \mathrm{Q}=1,14-1,83$, $\mathrm{Qm}=1,50$, elipsóides, hialinos, parede espessa e lisa, com poro germinativo bem distinto, dextrinóides (pseudoamilóides), congófilos, metacromáticos. Esporada branca (1.A1). Basídios (17-)19-24(-31)×9-10 $\mu \mathrm{m}$, clavados, hialinos, parede fina e lisa, com 4 esterigmas de 2-4 $\mu \mathrm{m}$ de comprimento. Pleurocistídios ausentes. Queilocistídios (21-)52-78(-108)×12-15(-17) $\mu \mathrm{m}$, variáveis em forma, clavados, ventricosos a lageniformes, hialinos, parede fina e lisa. Camada cortical do píleo formada por hifas hialinas de parede fina e lisa, prostradas e ramificadas, 4-14 $\mu \mathrm{m}$, apresentando elementos terminais eretos e de formatos diferentes, algumas vezes $(\mathrm{H}, \mathrm{T})$, onde se concentram as esquâmulas. Fíbulas ausentes. Trama himenoforal trabecular, formada por hifas hialinas de parede fina e lisa, 5-15(-20) $\mu \mathrm{m}$.

Hábito e habitat: gregário ou cespitoso, no solo ou em troncos de árvores caídas no interior da mata.

Material examinado: BRASIL. Rio Grande do Sul: Viamão, Parque Estadual de Itapuã, Praia da Pedreira, 22/X/2005, M.S. Rother 090/05 (ICN); Praia das Pombas, 18/IV/2006, M.S. Rother 132/06 (ICN).

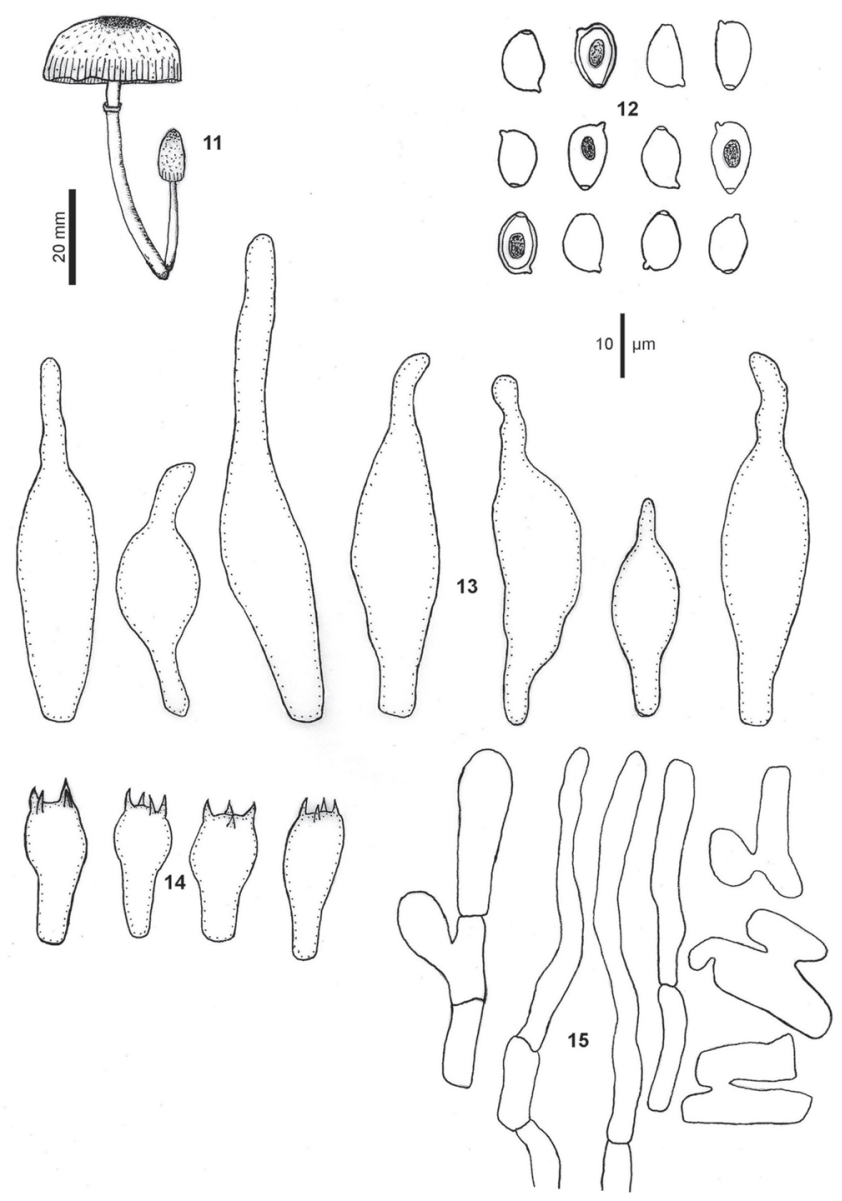

Figura 11-15. Leucocoprinus cepistipes (Sowerby) Pat. 11. Basidioma. 12. Basidiósporos. 13. Queilocistídios. 14. Basídios. 15. Elementos da camada cortical do píleo. 
Distribuição: Europa: Bon (1981); Candusso \& Lanzoni (1990); Vellinga (2001). Ásia: Pegler (1972; 1986); Wasser (1993). África: Heinemann (1977); Pegler (1977; 1983). Américas: Capelari \& Maziero (1988); Dennis (1952; 1970); Singer \& Digilio (1951); Smith \& Weber (1982); Pegler (1997); Wright \& Albertó (2002).

Comentários: espécie tipo do gênero, L. cepistipes é muito comum nas regiões tropicais e subtropicais (GuzmánDávalos \& Guzmán 1982). Caracteriza-se por apresentar basidiomas brancos cobertos por escamas flocosas de coloração castanho-claro a castanho-amarelado, píleo com margem plicada-estriada e basidiósporos com o poro germinativo evidente (Bon 1981; Candusso \& Lanzoni 1990; Heinemann 1997; Vellinga 2001; Wasser 1993). Embora essa espécie seja frequientemente citada, Smith \& Weber (1982) afirmam que seus limites morfológicos ainda necessitam ser mais delimitados. Como exemplo, pode ser citado o trabalho de Pegler (1986) que, segundo Vellinga (2001), trata erroneamente a espécie toda branca $L$. cretaceus (Bull.) Locq. como L. cepaestipes ( $=$ L. cepistipes). Todas as características do material coletado conferem com as dos materiais estudados por Candusso \& Lanzoni (1990), Dennis (1952; 1970), Heinemann (1977), Vellinga (2001) e Wasser (1993). No Brasil, L. cepistipes foi citada por Bononi et al. (1981; 1984) e Pegler (1997) para São Paulo, Capelari \& Maziero (1988) para Rondônia, Raithelhuber (1987a), Rick (1961), Singer (1953) e Sobestiansky (2005) para o Rio Grande do Sul, entre outros.

4. Leucocoprinus cretaceus (Bull.) Locq., Bull. mens. Soc. Linn. Lyon 14: 93 (1945).

Agaricus cretaceus Bull., Herb. France: pl. 374. 1788.

Fig. 16-20, 33

Píleo 30-70 mm, inicialmente hemisférico a campanulado, convexo a plano-convexo na maturidade, com ou sem um leve umbo; totalmente branco (1.A1), com superfície seca, coberta por esquâmulas flocosas brancas (1.A1), cônicas a piramidais; bordas planas com margem plicada; contexto carnoso a membranoso, de coloração branca, muito fino. Lamelas livres, brancas (1.A1), próximas, membranosas, apresentando lamélulas. Estípite 55-100×3-10 mm, central, cilíndrico com base alargada, branco tornando-se creme quando manipulado; superfície coberta ou não por esquâmulas flocosas, brancas do anel até a base; fistuloso, de consistência fibrosa; contexto branco. Anel superior, branco, simples, membranoso, fugaz. Odor desagradável.

Basidiósporos (8-)9-11(-12) $\times 5-7 \mu \mathrm{m}, \mathrm{Q}=1,33-2,00$, $\mathrm{Qm}=1,59$, elipsóides, hialinos, parede espessa e lisa, com poro germinativo bem distinto, dextrinóides (pseudoamilóides), congófilos, metacromáticos em Azul de Cresil. Esporada branca (1.A1). Basídios 16-24×8-10 $\mu \mathrm{m}$, clavados, hialinos, parede fina e lisa, com 4 esterigmas de 2-4 $\mu \mathrm{m}$ de comprimento. Pleurocistídios ausentes. Queilocistídios 30-63×8-15 $\mu \mathrm{m}$, estreitamente clavados, clavados, fusóides a ventricosos, hialinos, parede fina e lisa. Camada cortical do píleo formada por hifas hialinas de parede fina e lisa, de formas variadas $(\mathrm{H}, \mathrm{T}, \mathrm{Y}), 4-9 \mu \mathrm{m}$. Fíbulas ausentes. Trama himenoforal regular, formada por hifas hialinas de parede fina e lisa, 3-5 $\mu \mathrm{m}$.

Hábito e habitat: solitário, gregário ou cespitoso, sobre troncos de árvores vivas no interior da mata.

Material examinado: BRASIL. Rio Grande do Sul: Viamão, Parque Estadual de Itapuã, Praia da Pedreira, 9/IV/2005, M.S. Rother 024/05 (ICN); 22/X/2005, M.S. Rother 088/05 (ICN).

Distribuição: Europa: Bon (1981); Candusso \& Lanzoni (1990); Vellinga (2001). Ásia: Pegler (1986) como L. cepaestipes; Wasser (1993). África: Heinemann (1977). Américas: Meijer (2006); Sobestiansky (2005); Wartchow et al. (2008).

Comentários: esta interessante espécie é caracterizada macroscopicamente por apresentar basidiomas totalmente brancos, cobertos por escamas flocosas, facilmente removidas durante o manuseio, presentes tanto no píleo quanto no estípite (Heinemann 1977; Vellinga 2001). Segundo Candusso \& Lanzoni (1990) esta espécie é talvez a mais comum do gênero e seguramente a maior em dimensão, podendo ultrapassar $10 \mathrm{~cm}$ de diâmetro pilear. Todas as características dos materiais examinados conferem com as

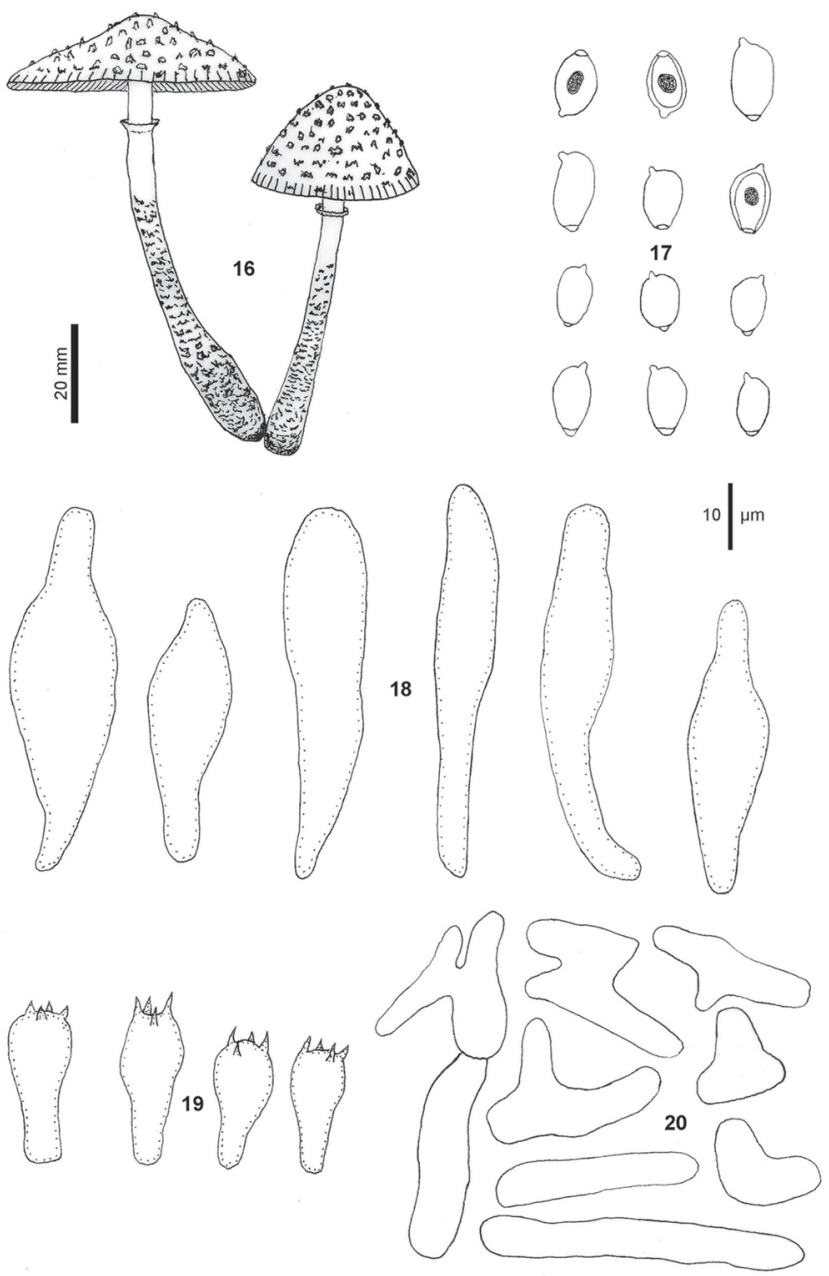

Figura 16-20. Leucocoprinus cretaceus (Bull.) Locq. 16. Basidioma. 17. Basidiósporos. 18. Queilocistídios. 19. Basídios. 20. Elementos da camada cortical do píleo. 
encontradas por Bon (1981), Candusso \& Lanzoni (1990), Vellinga (2001) e Wasser (1993), embora coletados em troncos de dicotiledôneas arbóreas vivas, substrato não mencionado por esses autores. Entretanto, vários outros substratos são citados, tais como solo, restos de madeira e serragem, e em casas de vegetação ou ao ar livre (Vellinga 2001). Pegler (1986) cita $L$. cretatus Locq. ex Lanzoni (= L. cretaceus) como sinonímia de L. cepaestipes (Sow.:Fr.) Pat. [= L. cepistipes (Sowerby) Pat.]. No entanto, Candusso \& Lanzoni (1990), Vellinga (2001) e Wasser (1993) tratam L. cepaestipes como uma espécie à parte, porque as escamas têm coloração castanha. No Brasil, L. cretaceus foi citado para os estados de Pernambuco (Wartchow et al. 2008), Paraná (Meijer 2006) e Rio Grande do Sul (Sobestiansky 2005). Esta é a segunda citação da espécie para o Rio Grande do Sul, mas acredita-se que já tenha sido coletada anteriormente no Estado e também no território brasileiro, porém identificada erroneamente como L. cepaestipes.

5. Leucocoprinus fragilissimus (Berk. \& M.A. Curtis) Pat., Essai Hymen. (Lons-le-Saunier): 171 (1900).

Hiatula fragilissima Ravenel \& Berk. Ann. Mag. Nat. Hist. Ser. II, 12: 422 (1853).

Fig. 21-24, 34

Píleo 20-35 mm, aplanado na maturidade, umbonado; branco (1.A1) a branco-amarelado (1.A2), com umbo mais amarelado (4.C4); superfície seca, quase translúcida, coberta por minúsculas esquâmulas, de coloração branco-amarelada; bordas planas, com margem plicada até o centro; contexto membranoso, muito fino, de coloração branca. Lamelas livres, colariadas, brancas, próximas, membranosas, apresentando lamélulas. Estípite 50-70×3 mm, central, cilíndrico, brancopálido; superfície com poucas e minúsculas esquâmulas flocosas; fistuloso, de consistência fibrosa; contexto branco. Anel mediano a súpero, branco, simples, ascendente, membranoso, afunilado e fino. Odor não verificado.

Basidiósporos (8-)9-12(-14)×6-8 $\mu \mathrm{m}, \mathrm{Q}=1,33-1,87$, $\mathrm{Qm}=1,56$, elipsóides, hialinos, parede espessa e lisa, com poro germinativo bem distinto, dextrinóides, congófilos, metacromáticos em Azul de Cresil. Esporada branca (1.A1). Basídios (19-)21-28(-30)×9-12(-14) $\mu \mathrm{m}$, clavados, hialinos, parede fina e lisa, com 4 esterigmas de 1,5-3 $\mu \mathrm{m}$ de comprimento. Pleurocistídios ausentes. Queilocistídios não visualizados. Camada cortical do píleo formada por hifas hialinas, prostradas e pouco ramificadas, de parede fina e lisa, 5-18 $\mu \mathrm{m}$, apresentando esferocistos e alguns elementos terminais levemente eretos onde se concentram as fibrilas. Fíbulas ausentes. Trama himenoforal trabecular, formada por hifas hialinas, de parede fina e lisa, 3-14 $\mu \mathrm{m}$.

Hábito e habitat: solitário ou gregário, encontrado no solo no interior da mata.

Material examinado: BRASIL. Rio Grande do Sul: Viamão, Parque Estadual de Itapuã, Encosta do Morro da Grota, 1/IV/2006, M.S. Rother 117/06 (ICN); Praia da Pedreira, 31/I/2004, P. S. Silva 041/04 (ICN); 9/IV/2005, M.S. Rother 004/05 (ICN).
Distribuição: Europa: Bon (1981); Candusso \& Lanzoni (1990). Ásia: Pegler (1972; 1986). África: Heinemann (1977). Américas: Albuquerque et al. (2006); Franco-Molano et al. (2000); Halling \& Mueller (2005); Meijer (2006); Pegler (1983; 1997); Smith \& Weber (1982); Wartchow et al. (2008).

Comentários: Leucocoprinus fragilissimus é facilmente diferenciado pela consistência membranácea dos basidiomas. A coloração amarelada é geralmente mais clara e mais pálida do que a encontrada em L. birnbaumii. Foram encontrados vários basidiomas desta espécie no Parque, que, devido a sua fragilidade, desfazendo-se rapidamente após a coleta, foram de difícil preservação no deslocamento até o laboratório. Segundo Pegler (1983), esta é provavelmente uma espécie pantropical comum, mas raramente coletada devido à consistência extremamente delicada e quase deliqüescente do basidioma. Todas as principais características do material coletado conferem com as citadas por Bon (1981), Candusso \& Lanzoni (1990), Franco-Molano et al. (2000), Halling \& Mueller (2005), Heinemman (1977) e Pegler (1972; 1983; 1986; 1997). Smith \& Weber (1982) citam a presença de queilocistídios clavados de 13-25(-36)×9-15 $\mu$ m, não mencionados pelos demais autores. Esta característica é de difícil visualização, pois as lamelas colapsam facilmente. Leucocoprinus fragilissimus é comumente encontrada nas regiões tropicais e subtropicais (Halling \& Mueller 2005), sendo a sua ocorrência muito rara nas regiões temperadas (Candusso \& Lanzoni 1990). A espécie foi citada para São Paulo (Bononi et al. 1981; Capelari 1989; Pegler 1997), Paraná (Meijer 2006), recentemente para Pernambuco (Wartchow et al. 2008) e para o Rio Grande do Sul (Albuquerque et al. 2006), sendo este trabalho o segundo registro para o Estado.

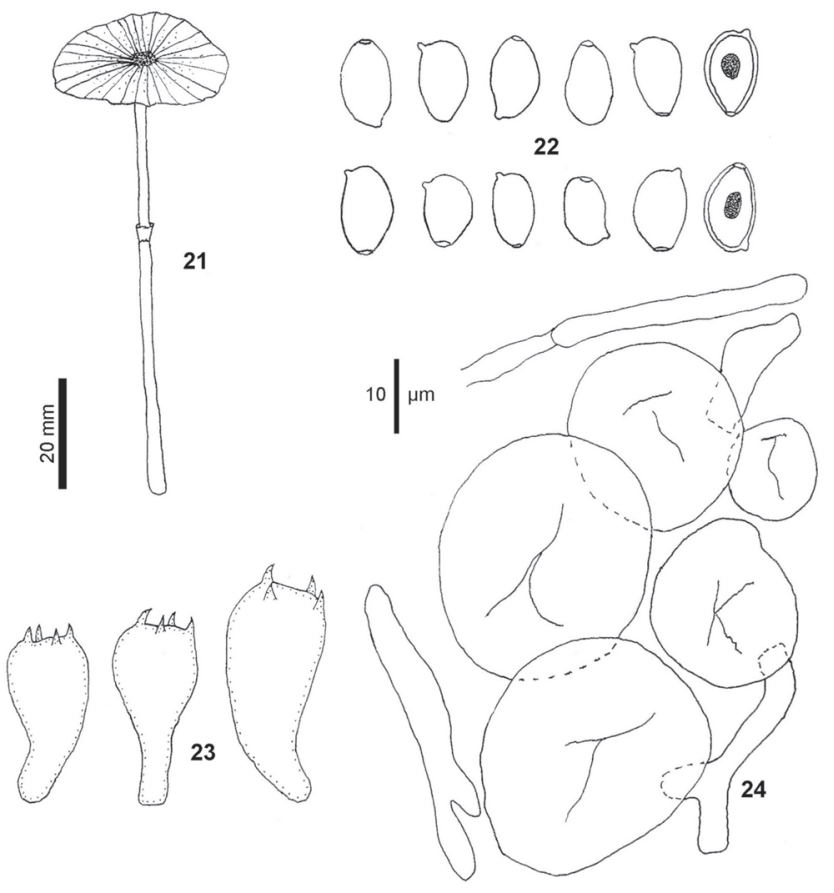

Figura 21-24. Leucocoprinus fragilissimus (Berk. \& M.A. Curtis) Pat. 21. Basidioma. 22. Basidiósporos. 23. Basídios. 24. Camada cortical do píleo com esferocistos. 

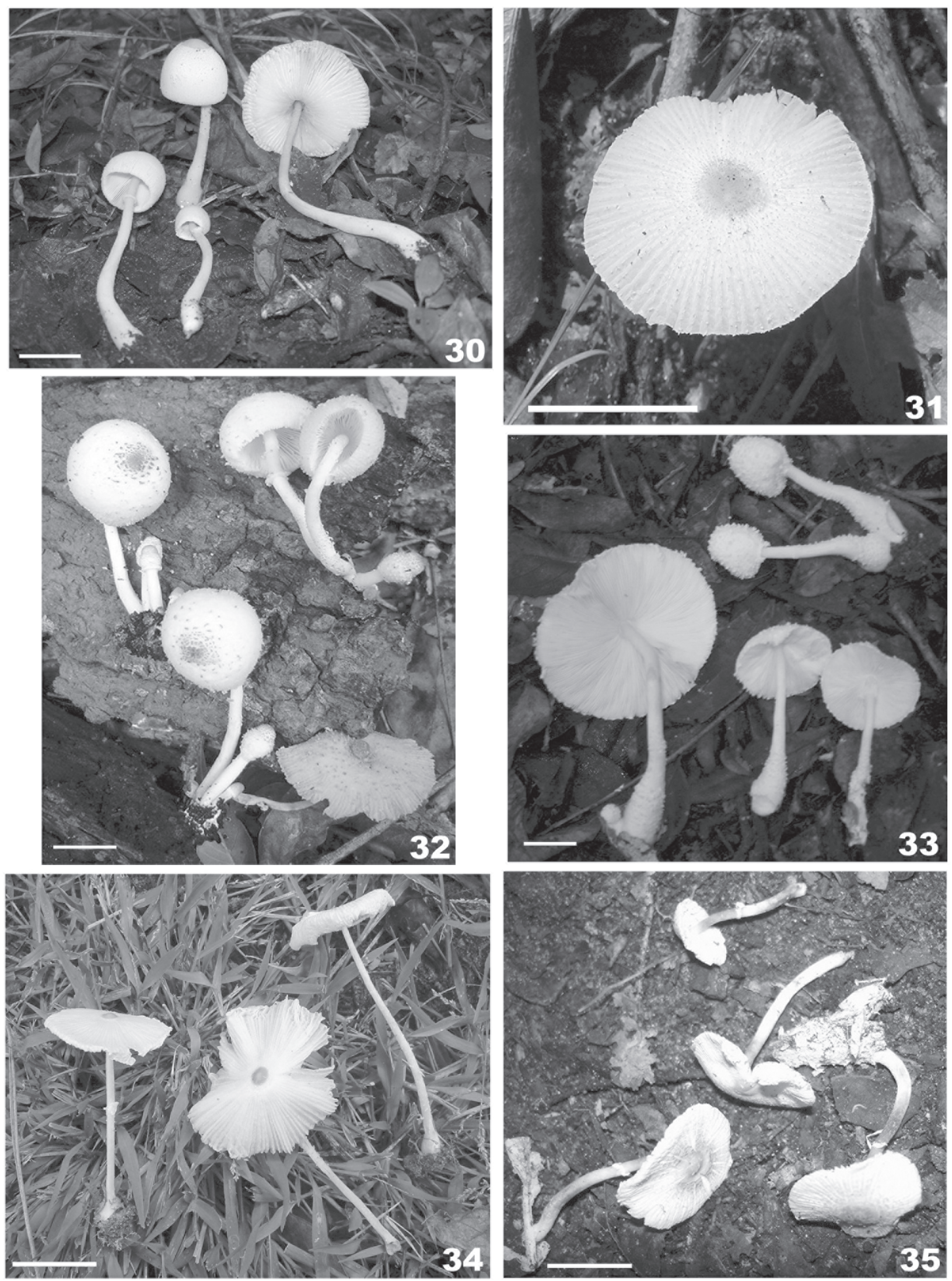

Figuras 30-35. Basidiomas. 30. Leucocoprinus birnbaumii (Corda) Singer. 31. Leucocoprinus brebissonii (Godey) Locq. 32. Leucocoprinus cepistipes (Sowerby) Pat. 33. Leucocoprinus cretaceus (Bull.) Locq. 34. Leucocoprinus fragilissimus (Berk. \& M.A. Curtis) Pat. 35. Leucocoprinus cf. medioflavus (Boud.) Bon. 
6. Leucocoprinus cf. medioflavus (Boud.) Bon, Doc. Mycol. 6 (no. 24): 45 (1976).

Lepiota medioflava Boud., Bull. Soc. mycol. Fr. 10: 59 (1894). Fig. 25-29, 35

Píleo 19-30 mm, convexo tornando-se aplanado na maturidade, umbonado; branco (1.A1) com o umbo castanho-claro (6.D8); superfície esquamulosa-fibrilosa, seca, coberta por esquâmulas flocosas, de coloração amarelo-pálido (1.A3) a castanho-amarelado (5.C7); borda curvada para baixo com margem plicada até a metade do píleo, variando algumas vezes até o início do umbo; contexto membranoso, muito fino, de coloração branca. Lamelas livres, brancas (1.A1), próximas, membranosas, apresentando lamélulas. Estípite 28-37×2-4 mm, central, cilíndrico com base levemente mais alargada, branco apresentando tons avermelhados; superfície lisa; fistuloso, de consistência fibrosa; contexto branco; rizomorfas minúsculas brancas; micélio basal ausente. Anel súpero, simples, ascendente, membranoso, branco, fugaz. Odor não verificado.

Basidiósporos (4,6-)5-6,5(-7)×(2,6-)3-4 $\mu \mathrm{m}, \mathrm{Q}=1,60-2,00$, $\mathrm{Qm}=1,83$, elipsóides a oblongos, hialinos, parede fina $\mathrm{e}$ lisa, não apresentando poro germinativo visível; inamilóides, congófilos, metacromáticos em Azul de Cresil. Esporada branca (1.A1). Basídios 17-23×5,5-7,5 $\mu \mathrm{m}$, clavados, hialinos, parede fina e lisa, com 4 esterigmas de 1,5-3 $\mu \mathrm{m}$ de comprimento. Pleurocistídios ausentes. Queilocistídios (15-)19-42(-50)×9-16 $\mu \mathrm{m}$, clavados, hialinos, abundantes, de parede fina e lisa. Camada cortical do píleo formada por hifas hialinas, prostradas, de parede fina e lisa, 3-16 $\mu \mathrm{m}$. Fíbulas ausentes. Trama himenoforal trabecular, formada por hifas hialinas de parede fina e lisa, 4-13 $\mu \mathrm{m}$.

Hábito e habitat: solitário ou gregário, em solo ou na serrapilheira no interior da mata.

Material examinado: BRASIL. Rio Grande do Sul: Viamão, Parque Estadual de Itapuã, Encosta do Morro da Grota, 25/VI/2005, M.S. Rother 060/05 (ICN); Praia da Pedreira, 25/VI/2005, M.S. Rother 061/05 (ICN); 7/IX/2005, M.S. Rother 077/05 (ICN).

Distribuição: Europa: Bon (1981); Candusso \& Lanzoni (1990). África: Heinemann (1977).

Comentários: Leucocoprinus medioflavus é caracterizada por apresentar basidiósporos sem poro germinativo visível e superfície pilear desprovida de esferocistos (Bon 1981; Candusso \& Lanzoni 1990; Heinemann 1977), características observadas nos exemplares coletados. Porém, os autores não mencionam se os basidiósporos são dextrinóides. No material examinado os basidiósporos não são dextrinóides. Esta característica não é comum no gênero, mas é encontrada também em L. longistriatus (Peck) H.V. Sm. \& N.S. Weber. Entretanto, segundo Smith \& Weber (1982) esta espécie apresenta basidiomas maiores que os de L. medioflavus, coloração diferente e basidiósporos com dimensões maiores 6-8(-9)×4,5-5 $\mu \mathrm{m}$. Caso sua identificação seja confirmada, trata-se do primeiro registro para a América do Sul.
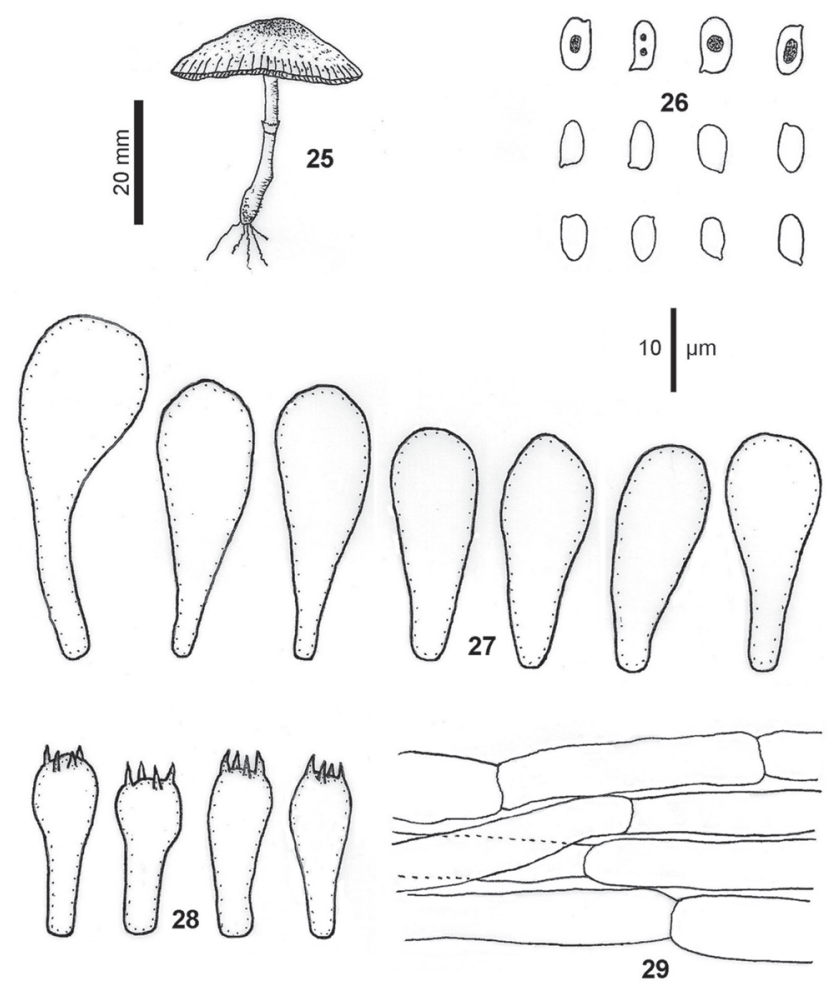

Figura 25-29. Leucocoprinus cf. medioflavus (Boud.) Bon. 25. Basidioma. 26. Basidiósporos. 27. Queilocistídios. 28. Basídios. 29. Hifas da camada cortical do píleo.

\section{Agradecimentos}

Ao CNPq (Conselho Nacional de Desenvolvimento Científico e Tecnológico), pelo financiamento do projeto e a SEMA-RS (Secretaria Estadual do Meio Ambiente) do Estado do Rio Grande do Sul, por permitir o trabalho no Parque Estadual de Itapuã. O primeiro autor agradece à CAPES (Coordenação de Aperfeiçoamento de Pessoal de Nível Superior), pela bolsa de Mestrado e auxílio financeiro.

\section{Referências bibliográficas}

Albuquerque, M.P.; Victoria, F.C. \& Pereira, A.B. 2006. Ecologia e distribuição do gênero Leucocoprinus Pat. no Rio Grande do Sul, Brasil. Acta Biologica Leopondensia 28: 11-16.

Bon, M. 1981. Cle Monographique Des “Lepiotes" D'Europe. Documents Mycologiques 11: 1-77.

Bononi, V.L.R.; Trufem, S.F.B. \& Grandi, R.A.P. 1981. Fungos macroscópicos do Parque Estadual das Fontes do Ipiranga, São Paulo, Brasil, depositados no herbário do Instituto de Botânica. Rickia 9: 37-53

Bononi, V.L.R.; Mucci, E.S.F.; Yokomizo, N.K.S. \& Guzmán, G. 1984. Agaricales (Basidiomycetes) do Parque Estadual de Campos do Jordão, SP, Brasil. Rickia 11: 85-89.

Breitenbach, J. \& Kränzlin, F. 1995. Champignons de Suisse. Tome 4/ Pars 2: Entolomataceae, Pluteaceae, Amanitaceae, Agaricaceae, Coprinaceae, Bolbitiaceae et Strophariaceae. Lucerne, Mykologia Lucerne.

CABI Bioscience Database, 2008. Index Fungorum - Authors of Fungal Names http://www.indexfungorum.org/Names/ AuthorsOfFungalNames.asp (Acessado em 4/08/2008).

Candusso, M. \& Lanzoni, G. 1990. Lepiota s.I. Fungi Europei 4. Saronno, Giovanna Biella.

Capelari, M. 1989. Agaricales do Parque Estadual da Ilha do Cardoso (exceto Tricholomataceae). Dissertação de Mestrado. São Paulo, Universidade de São Paulo. Curso de Pós-Graduação em Botânica. 
Capelari, M. \& Gimenes, L.J. 2004. Leucocoprinus brunneoluteus, uma nova espécie de Agaricaceae. Hoehnea 31: 331-335.

Capelari, M. \& Maziero, R. 1988. Fungos macroscópicos do estado de Rondônia, região dos Rios Jaru e Ji-Paraná. Hoehnea 15: 28-36.

Dennis, R.W.G. 1952. Lepiota and allied genera in Trinidad, British West Indies. Kew Bulletin 7: 459-499.

Dennis, R.W.G. 1961. Fungi Venezuelani: IV Agaricales. Kew Bulletin 15: $67-156$

Dennis, R.W.G. 1970. Fungus Flora of Venezuela and Adjacent Countries. Kew Bulletin Additional Series 3: 1-531.

Franco-Molano, A.E.; Aldana-Gómez, R. \& Halling, R. 2000. Setas de Colombia (Agaricales, Boletales y otros hongos) Guía de campo. Medellín. Multimpresos.

Grandi, R.A.P.; Guzmán, G. \& Bononi, V.L. 1984. Adições às Agaricales (Basidiomycetes) do Parque Estadual Fontes do Ipiranga, São Paulo, SP, Brasil. Rickia 11: 27-33.

Guzmám-Dávalos, L. \& Guzmán, G. 1982. Contribucion al conocimiento de los Lepiotaceos (Fungi, Agaricales) de Quintana Roo. Boletín de la Sociedad Mexicana de Micologia 17: 43-54.

Halling, R.E. \& Mueller, G.M. 2005. Common Mushrooms of the Talamanca Mountains, Costa Rica. Memoirs of the New York Botanical Garden, v. 90.

Heinemann, P. 1977. Flore Illustrée Des Champignons d'Afrique Centrale. Leucocoprinus (Agaricaceae). Bull. Jard. Bot. Nat. Belg. 5: 87-109.

Kirk, P.M.; Cannon, P.F.; David, J.C. \& Stalpers, J.A. 2001. Ainsworth \& Bisby's Dictionary of Fungi. $9^{\text {th }}$ ed. Cambridge. CAB International.

Kornerup, A. \& Wanscher, J.H. 1978. Methuen Handbook of Colour. $3^{\text {rd }}$ ed. London, Eyre Methuen.

Largent, D.L. 1977. How to identify mushrooms to genus I: Macroscopic features. Eureka, Mad River Press Inc.

Largent, D.L.; Johnson, D. \& Watling, R. 1986. How to identify mushrooms to genus III: microscopic features. Eureka, Mad River Press Inc.

Meijer, A.A.R. 2001. Mycological work in the Brazilian state of Paraná. Nova Hedwigia 72: 105-159.

Meijer, A.A.R. 2006. Preliminary List of the Macromycetes from the Brazilian State of Paraná. Boletim do Museu Botânico Municipal 68: 1-59.

Pegler, D.N. 1972. A revision of the genus Lepiota from Ceylon. Kew Bulletin 27: 155-202.
Pegler, D.N. 1977. A Preliminary Agaric Flora of East Africa. Kew Bulletin Additional Series 6: 1-615.

Pegler, D.N. 1983. The Agaric Flora of Lesser Antilles. Kew Bulletin Additional Series 9: 1-668.

Pegler, D.N. 1986. Agaric Flora of Sri Lanka. Kew Bulletin Additional Series 12: 1-519.

Pegler, D.N. 1997. The Agarics of São Paulo, Brazil. Kew, Royal Botanic Gardens.

Raithelhuber, J. 1987a. Die gattung Leucocoprinus in den ABCStaaten. Metrodiana 15: 5-17.

Raithelhuber, J. 1987b. Die gattung Leucocoprinus in den ABCStaaten. Metrodiana 15: 35-44.

Rick, J. 1961. Basidiomycetes Eubasidii in Rio Grande do Sul - Brasilia 5. Agaricaceae. Iheringia, Série Botânica 8: 296-450.

Silva, P.S.; Cortez, V.G. \& Silveira, R.M.B. 2006. The mycobiota of Itapuã Park, Rio Grande do Sul, Brazil. I. Species of Strophariaceae. Mycotaxon 97: 219-229.

Singer, R. 1953. Type studies on Basidiomycetes VI. Lilloa 26: 57-159.

Singer, R. 1986. The Agaricales in Modern Taxonomy. $4^{\text {th }}$ ed. Koenigstein, Koeltz Scientific Books.

Singer, R. \& Digilio, A.P.L. 1951. Pródromo de la flora Agaricina Argentina. Lilloa 25: 5-461.

Smith, H.V. \& Weber, N.S. 1982. Selected species of Leucocoprinus from Southeastern United States. Contributions form the University of Michigan Herbarium 15: 297-309.

Sobestiansky, G. 2005. Contribution to a Macromycete Survey of the States of Rio Grande do Sul and Santa Catarina in Brazil. Brazilian Archives of Biology and Technology 48: 437-457.

Vellinga, E.C. 2001. Leucocoprinus. In Flora Agaricina Neerlandica: critical monographs on families of agarics and boleti occurring in the Netherlands. (M.E. Noordeloos, T.H.W. Kuyper \& E.C. Vellinga, eds.). A.A. Balkema Publishers, Lisse, Abingdon, Exton, Tokyo, 5: 76-84.

Vellinga, E.C. 2004. Genera in the family Agaricaceae: Evidence from nrITS and nrLSU sequences. Mycological Research 10: 352-377.

Wartchow, F. Putzke, J. \& Cavalcanti, M.A.Q. 2008. Agaricaceae Fr. (Agaricales, Basidiomycota) from areas of Atlantic Forest in Pernambuco, Brazil. Acta Botanica Brasilica 22: 287-299.

Wasser, S.P. 1993. Tribes Cystodermateae Sing. and Leucocoprineae Sing. of the CIS and Baltic States. Libri Botanici 9: 1-105.

Wright, J.E. \& Albertó, E. 2002. Guía de los Hongos de La Región Pampeana. I. Hongos con Laminillas. Buenos Aires, L.O.L.A. 